\title{
Adam Smith y los límites a la naturaleza
}

\section{Hernán Gabriel Borisonik*}

Universidad Nacional de San Martín

hborisonik@unsam.edu.ar
Revista Cultura Económica

Año XXXIX • N¹01

Junio 2021: 11-31

https://doi.org/10.46553/cecon.39.101.2021.p11-31

Resumen: El presente artículo comienza dando una muestra general de la tendencia moderna a ver leyes regulares en los comportamientos económicos y a desplazar lo social en función de lo individual. Frente a eso, busca en el pensamiento de Adam Smith algunas pistas para recuperar una idea de naturaleza que no sea absoluta y una apelación intermitente a la necesidad de tomar medidas políticas cuando sean necesarias, incluso si se oponen a los designios naturales. Para eso se describirán tres de sus categorías centrales, se tomarán algunos dichos de John Locke sobre la propiedad y se analizará el gran incendio que azotó a Londres en 1666, así como la génesis de las brigadas de bomberos. Con todo lo anterior, se buscará echar luz sobre algunos aspectos menos atendidos del cruce entre Estado, mercado y vida nacional en la obra smithiana.

Palabras clave: Adam Smith; Naturaleza; Ley civil

\section{Adam Smith and the Limits to Nature}

Abstract: This article begins by giving a general snapshot of the modern tendency to see regular laws in economic behavior and to displace the social in favor of the individual. In view of that, it searches Adam Smith's thought for some clues to recover an idea of nature that is not absolute and an intermittent appeal to the need to take political measures when necessary, even if they oppose natural designs. For this, three of Smith's central categories are described, together with some sayings of John Locke about the property and a description of the Great Fire that struck London in 1666 (as well as the genesis of the fire brigades). With all of the above in mind, it will seek to shed light on some less-attended aspects of the intersection between State, market and national life in Smithian work.

Keywords: Adam Smith; Nature; Civil law

* Recibido: 05/04/2021 - Aprobado: 24/05/2021 


\section{Introducción}

"Natural" y "naturaleza" son, parafraseando a Spencer Pack (1995), palabras cargadas de complejidad, ambigüedad y contradicción. Vincular de forma explícita ley civil o cultura a intervención estatal y naturaleza a autorregulación y mercado puede correr el riesgo de simplificar en exceso los matices y perspectivas con los que estos términos fueron tratados. Esto se aplica especialmente a Adam Smith, quien no utilizó tales conceptos de modo inmutable y por lo tanto habilitó lecturas complementarias (cuando no contrapuestas), que no deberían ser descartadas sin miramientos. Es común dentro de la obra de Smith encontrar comparaciones entre lo que puede considerarse justo y lo que hacen los hombres de acuerdo a las inclinaciones que poseen "naturalmente" y no en todos los casos, ni obligatoriamente, hay una directa predilección por la segunda de esas opciones. De hecho, un sostén central para la presente reflexión es una cita del propio Smith, sobre la que se volverá más tarde, acerca de las normas contra formas de emisión privada de dinero:

Estas reglamentaciones pueden considerarse indiscutiblemente como contrarias a la libertad natural. Pero el ejercicio de esta libertad por un contado número de personas, que puede amenazar la seguridad de la sociedad entera, puede y debe restringirse por la ley de cualquier Gobierno (Smith, 1997: 293).

Por eso, concordamos con la afirmación de Pack que sostiene que "un estudio, análisis y/o interpretación del trabajo de Smith que dependa de esta suposición (a veces no declarada) -que Smith necesariamente aprobaba la 'naturaleza' o lo 'natural'- debe leerse con gran cuidado; quizás incluso con incredulidad" (Pack, 1995: 1).

La dicotomía entre naturaleza y cultura representa uno de los clivajes que ha tensado a la Modernidad con mayor insistencia y permanencia. Por eso, uno de los nudos centrales del período se encuentra en el Estado, instancia en la que las sociedades han debido resolver las tensiones entre ambos polos de la existencia humana. Pero en todos los casos, las normas y regulaciones que fueron surgiendo respondieron a un punto nuclear en el que lo dado y lo producido se presentan como indistinguibles: la llamada naturaleza humana, una esencia o tendencia a la que se apeló desde cada tradición de pensamiento para justificar los modos de organización colectiva. Sin embargo, la racionalidad, la sensibilidad y las inclinaciones, 
que cada discurso intuyó de manera particular, fueron siempre elementos cardinales de toda caracterización de lo humano.

Si bien el proceso moderno comenzó con una luz de sospecha hacia los hombres -tanto Hobbes $(1987 ;$ 1996) como Maquiavelo (1984), conocidos como los padres del pensamiento filosófico-político moderno, desconfiaban de los sujetos individuales sin control estatal-, tal impresión fue modulándose hacia concepciones más amables, en concordancia con el establecimiento del parlamentarismo representativo en Europa y los Estados Unidos. Esto coincidió con una paulatina superación de los privilegios medievales y la dominación extraeconómica feudal a favor de una lenta pero permanente despersonalización de los vínculos sociales y la construcción de relaciones basadas en los contratos y la obtención de ganancias.

Tal metamorfosis tuvo como efecto que se pasara de pensar en la conveniencia de la soberanía absoluta, como límite eficaz a las ansias individuales, a la búsqueda de instancias que pudieran demarcar (o eventualmente frenar) a los órganos y miembros del poder político, con el fin de que no se volvieran obstáculos para las acciones de los gobernados ni usaran el gobierno como instrumento para su beneficio personal. Del mismo modo, la preocupación central se fue moviendo desde las ideas de control y afianzamiento institucional a principios como progreso, iniciativa $o$ equilibrio; y de concebir a la naturaleza como algo a refrenar se pasó a verla como un elemento al que en principio había que dejar fluir. Adam Smith puede ser contado como uno de los eslabones en esa cadena tendiente a un cierto optimismo en relación con las inclinaciones naturales de los individuos. Para este nativo de Kirkcaldy, los humanos están afectados por tendencias armoniosas, que los encaminan a un desarrollo cada vez mayor.

Entre los siglos XVII y XIX, se consolidó asimismo una percepción generalizada de un mundo previsible. Gracias a la invención del cálculo de Leibniz y Newton, la predicción de la naturaleza a largo plazo se vuelve factible. Un ejemplo claro fue la deducción de Halley (en 1705) sobre el regreso del cometa que llevaría luego su nombre. Empezó a mentarse un mundo en el que existían leyes naturales pasibles de ser descubiertas racionalmente, cuya positivación daría ventajas a las sociedades. En ese período, se observa una creencia en la presencia de regularidades que encontró en la economía política una posibilidad de reconocer formas invariables del comportamiento social. Algunos de los casos más célebres son la ley de la oferta y la demanda proclamada por James Steuart (1767), la 
ley de la población hallada por Malthus (1798), la ley de los mercados divulgada por Say (1803), o la ley de la renta investigada por David Ricardo (1817).

Tal era el contexto en el que se conformó el pensamiento de Adam Smith. A pesar de que en su temprana recepción, exégetas como Wilhelm Paszkowsky (1890) o Albion Woodbury Small (1907) han señalado la importancia de la obra de Smith para la teoría política, la filosofía y la sociología, con el paso del tiempo esta fue cada vez menos tomada desde su arista reflexiva y más interpretada desde un prisma casi técnico que empobrece su legado. Pues, más allá de los indudables aportes que Smith ha realizado en el campo de la economía política, una recepción puramente economicista soslaya significativamente otros fructíferos y relevantes aspectos de una obra que fue concebida desde el prisma de la filosofía moral integral. Recordemos que, lejos de las contiendas en las que hoy (dos siglos y medio más tarde) se ve utilizado The Wealth of Nations, su escritura estaba atravesada por disputas contra el Ancien Régime, el mercantilismo y otras perspectivas, que fueron perdiendo peso y protagonismo.

Precisamente por eso, revisitar el papel de algunas categorías centrales de su pensamiento, como la mano invisible, la simpatía o el espectador imparcial nos podría ayudar en la construcción de lecturas especialmente atentas a la compleja relación que Smith establece entre naturaleza, ley y razón. Citando a Cremachi (1989: 104), Pack afirma que Smith usó los términos "naturaleza" y "natural"

como un vínculo metafísico entre la "realidad" o la "verdad" (que, siguiendo a Hume, Smith sintió que era incapaz de conocer o apropiarse o hacer "progresar") y el historicismo. Por lo tanto, hablar de la naturaleza y lo natural proporcionó a Smith un amortiguador o puente entre "la mente individual y el orden último de la realidad” (Pack, 1995: 18).

Del mismo modo, es central la pregunta acerca de las condiciones bajo las cuales la acción política se torna posible en su relación con la economía, ya que a partir de allí se abre un virtual diálogo entre Smith y los dilemas políticos de la sociedad global contemporánea, mostrando su vigencia y actualidad e incluso su potencia para pensar otras articulaciones posibles. Y si bien lo anterior excede de lejos las posibilidades de este artículo, al menos marca la perspectiva con la que fue escrito. 
Cabe resaltar que, aunque las circunstancias históricas hayan mutado enormemente desde el capitalismo comercial a nuestros días, las condiciones de vida actuales son de algún modo tributarias de aquel proceso que estableció al mercado como agente privilegiado (y naturalizado) para la distribución de bienes. La ciencia y la técnica modernas (desde la imprenta hasta Newton) marcaron, sin duda, los trazos más gruesos del camino. Sin embargo, existieron otros acontecimientos que también fueron modulando las ideas socialmente aceptadas, tales como las guerras o las catástrofes naturales, que incluso permearon de diversos modos los discursos filosóficos con la consciencia del real peligro de perder la vida, la sociedad o la civilización. Un caso ejemplar, en ese sentido, fue el importante terremoto de Lisboa en 1755, que puso en relevancia la inestabilidad de la vida frente a los cataclismos, despertando las reflexiones de intelectuales de la altura de Hume, Kant o Voltaire. Y otro, aún anterior, fue el Gran Incendio de Londres ocurrido en 1666.

De hecho, a través de un comentario de Smith sobre el fuego, es posible matizar algunas interpretaciones que proponen un desarrollo lineal y unívoco sobre su pensamiento acerca de la autorregulación y las intervenciones sobre la economía. Si bien hoy se conocen algunas de las inflexiones que la recepción de la obra de Smith ha sufrido en manos de sus intérpretes y la simplificación que se ha vulgarizado (Piqué, 2019), este trabajo busca recuperar en algún sentido aristas menos visitadas de ese legado.

En ese sentido, este texto busca poner el foco en el vínculo entre política y economía (como reflejo de las tensiones entre Estado y mercado, y entre sociedad y naturaleza) en el pensamiento de Smith, a partir del estudio de algunos hechos que giran en torno al gran fuego de 1666. Para eso, es fundamental recuperar el contexto del incendio, pero también comentar el surgimiento de las brigadas de bomberos y repasar algo de la perspectiva de John Locke frente a la distinción entre ley natural y ley civil.

\section{Tres categorías centrales en Smith}

No es raro hallar, en la obra smithiana, comparaciones entre lo que puede ser justo y lo que los hombres están "naturalmente" inclinados a hacer, y no en todos los casos, ni necesariamente, hay una directa predilección por la segunda de esas opciones. Acompañando, no sin tensiones, el proceso que centraría en el individuo el pensamiento moderno, Adam Smith realizó profundas meditaciones acerca de los modos en los que algunas categorías 
se traccionan y complementan. Tal vez por eso, lejos de definiciones estancas, presentó formulaciones complejas (menos dicotómicas que polares) entre ley natural y ley civil, individuo y sociedad, mercado y Estado. Dentro de esa constelación, nos parece importante exponer muy brevemente tres de sus más célebres conceptos, con el objeto de no asumirlos como datos a priori y aclarar una perspectiva de lectura para el resto del presente artículo.

Primero, la célebre mano invisible. Siguiendo a toda la tradición clásica, Smith encuentra dos ideas de riqueza: una individual, mensurable en dinero, y otra nacional, correspondiente al trabajo de todos los habitantes de un Estado (Ottonello, 2019). A la segunda apela el título La riqueza de las naciones y a ella apuntan las acciones de la mano invisible. Dicho de otro modo, si bien es claro que existen y pesan los intereses individuales, el centro de la preocupación de Smith es el desarrollo colectivo.

Observemos por un momento las dos alusiones más sustanciales a este concepto. Primero, en la Teoría de los sentimientos morales, la mano invisible hace que los más pudientes sirvan de ayuda a los menos favorecidos económicamente y (a través de la publicidad de su imagen victoriosa y admirada) los estimulan a trabajar y esforzarse más. Aquí se ve la íntima relación entre mano invisible y simpatía. Más precisamente, la mano invisible opera de mecanismo de paso de lo individual a lo colectivo.

Los ricos sólo seleccionan del conjunto lo que es más precioso y agradable. Ellos consumen apenas más que los pobres, y a pesar de su natural egoísmo y avaricia, aunque sólo buscan su propia conveniencia, aunque el único fin que se proponen es la satisfacción de sus propios vanos e insaciables deseos, dividen con los pobres el fruto de todas sus propiedades. Una mano invisible los conduce a realizar casi la misma distribución de las cosas necesarias para la vida que habría tenido lugar si la tierra hubiese sido dividida en porciones iguales entre todos sus habitantes, y así sin pretenderlo, sin saberlo, promueven el interés de la sociedad y aportan medios para la multiplicación de la especie. [...] Cuando un patriota se esfuerza para mejorar cualquier sección de la política pública, su conducta no surge invariablemente de la pura simpatía con la felicidad de quienes recogerán los beneficios de la misma. Cuando un hombre de vocación política aboga por la reparación de las carreteras no lo hace comúnmente porque se 
sienta solidario con transportistas y carromateros (Smith, 1997: 332-333).

Algo análogo ocurre en la infinitamente reproducida cita sobre el carnicero, el cervecero y el panadero de La riqueza de las naciones (Smith, 1996: 46). El hecho de que haya dos ideas de riqueza solapadas es lo que habilita que cada individuo busque su propia productividad, pero también beneficie a la sociedad y hace que los intereses particulares y los generales puedan armonizar. Sin embargo, la "riqueza real" es, para Smith, la nacional, siempre mediada por el trabajo. Por eso, no es tan grave que los sujetos compitan por obtener dinero, siempre que lo hagan a través del crecimiento del trabajo nacional. Pero, por eso mismo y en nombre de la nación, también se pueden poner frenos a algunas acciones privadas.

En segundo lugar, la simpatía es una capacidad natural basada en la posibilidad de imaginar un cambio de posición con la persona a la que se está juzgando. Implica un juego especular entre los miembros de una sociedad que allana el camino para una convivencia más armónica y a la vez marca una mediación social para cualquier acto individual (ya que, una vez comprendido el mecanismo, los sujetos piensan cómo serán juzgados y modulan sus acciones en consecuencia). Al principio de la Teoría de los sentimientos morales, hay un primer acercamiento a la idea de simpatía: "nuestra compañía en el sentimiento ante cualquier pasión ajena" (Smith, 1997: 52). Posee un componente natural, pero no es independiente del contexto: "la simpatía no emerge tanto de la observación de la pasión como de la circunstancia que la promueve" (Smith, 1997: 54). No es una reacción mecánica o abstracta, sino mediada por la comprensión de la situación específica. Y en esa mediación participan la razón y la imaginación. Por eso, la simpatía no es contagio, compasión o justificación de lo hecho, sino el resultado de un proceso mental a raíz de una acción específica. Entonces, como "nada nos agrada más que comprobar que otras personas sienten las mismas emociones que laten en nuestro corazón y nada nos disgusta más que observar lo contrario" (Smith, 1997: 57), la simpatía hacia los demás es también responsable de nuestras acciones en público.

En relación con ello, la simpatía smithiana es una práctica social, que cada individuo realiza a lo largo de su vida (lo cual hace que mejore en su ejercicio) y que tiene como efecto el sostén (o incluso la producción) de una ética no previa ni universal, sino histórica: 
la presente investigación no aborda una cuestión de derecho, por así decirlo, sino una cuestión de hecho. No examinamos aquí las circunstancias bajo las cuales un ser perfecto aprobaría el castigo de las acciones malas, sino bajo qué principios una criatura tan débil e imperfecta como el ser humano lo aprueba de hecho y en la práctica (Smith, 1997: 168).

La simpatía siempre se da en un contexto en el que se halla algún vínculo (por ejemplo, cultural o familiar) entre el agente y el público. Y, del mismo modo, es una instancia que toda construcción político institucional debería presuponer.

Como sea, considerar su carácter perfectible es fundamental, ya que Smith encuentra en la naturaleza también cosas abominables, como

un amor por la dominación y la autoridad sobre los demás, que me temo que es natural para la humanidad, un cierto deseo de tener a otros por debajo de uno, y el placer que da a uno tener a alguien a quien pueda ordenar que haga su trabajo en lugar de verse obligado a persuadir a otros para que negocien con él (Smith, 1982b: 130).

Lo natural en los humanos es, según Smith, algo a mejorar, a través de las costumbres, la educación e incluso a veces a limitar a través de las leyes civiles.

Por eso, en tercer lugar, el espectador imparcial viene a completar la arquitectura social de la simpatía, pues despliega un espacio neutral, por fuera de los intereses de quien está juzgando. Tan histórico y situado como la primera, este constituye una instancia más compleja y elaborada, por lo que es presentado como algo a lo que debería tenderse a concebir. Smith lo llama de varios modos, siempre en tono de loa, como semidiós o "el tribunal de sus propias conciencias, [...] el del hombre dentro del pecho, el alto juez y árbitro de su conducta" (Smith, 1997: 251). El espectador imparcial representa el punto más elaborado y logrado de la tendencia a la simpatía. Es un norte moral que cada individuo tiene que lograr componer. Y, como se decía más arriba, es una construcción que conduce a una mejor sociedad, no como autorregulación automatizada, sino como proceso dinámico que nutre a (tanto como se alimenta de) las leyes y regulaciones formales.

En las tres categorías aquí esquemáticamente presentadas, se encuentran espacios oscuros en los que lo natural y lo civil son difícilmente 
separables, pues se encadenan y delimitan mutuamente de modo que no siempre hay una respuesta clara a los problemas históricos que enfrentan las naciones. Recordemos que en La riqueza de las naciones Smith señala que es necesario tener ciertas reservas frente al libre comercio, sobre todo éticas. Pues, si bien aseguró que existe una natural e innata propensión del ser humano a "trocar, permutar y cambiar una cosa por otra" (Smith, 1996: 14) en los humanos, también "dedicó una atención escrupulosa a las contradicciones subyacentes de la economía de mercado" (Nolan, 2003: 122). Así, mientras veía en el libre mercado un impulso inigualable para la economía, "demostró que este motor contenía profundas contradicciones internas, considerando que los hombres son simultáneamente productores y consumidores" (Nolan, 2003: 122). Smith era consciente de que para que la competencia funcione correctamente, el sistema social debe minimizar la capacidad de los más poderosos para usar su autoridad sobre los demás.

\section{Los sucesos del gran incendio}

El Great Fire of London fue la primera catástrofe moderna de Inglaterra, aunque también fue un catalizador para ese período. Su llegada fue parte de un ciclo de situaciones aciagas (como la peste bubónica y las guerras con Francia y Holanda) que aceleraron las rupturas con las costumbres medievales, a lo que se sumó la cifra 1666 (de fuertes implicancias religiosas). Durante la primera semana de septiembre de ese año, el centro de Londres (desde la Pudding Lane, a pocos metros del río Támesis, hasta la Pye Corner, en una línea de alrededor de 1,5km) ardió con fuerza, arrasando con varias construcciones icónicas como la catedral de Saint Paul y los muros de la ciudad y dejando una humareda que siguió emergiendo de las ruinas durante más de seis meses (Davis, 1923). El evento fue de tal magnitud que se han erigido recordatorios, aún visibles, en los puntos de su inicio y desenlace. Por un lado, la gran columna dórica llamada The Monument y, por el otro, el pequeño Golden Boy of Pye Corner (Walker, 2011).

En la época, existieron diversas explicaciones acerca del incendio. Sobre su origen, parte de los exégetas lo atribuían a causas políticas, tanto externas (las contiendas con otros países) como intestinas (Maitland, 2010: 435). Otra versión se centraba en causas teológicas, como castigos divinos (Stillingfleet, 1666: 14; Gilpin, 2013) o denuncias de protestantes contra los católicos, como en el caso de Hume, quien en su Historia de Inglaterra inculpó sin dudarlo a la orden jesuita (Hume, 1983: 337). Sin embargo, hoy se sabe que la procedencia del incendio fue mucho más profana $\mathrm{y}$ 
contingente; provino del horno de la panadería de Faryner que él mismo o alguno de sus ayudantes olvidaron apagar, tal y como lo declaró el Committee to Enquire into the Burning of London (1667). Su rápida y brutal expansión se debió a las condiciones climáticas (especialmente eólicas) del momento. La violencia de las llamas destruyó un porcentaje tan grande de la Londres del siglo XVII (Clout, 2000: 60-68), que incluso hizo pensar a sus habitantes que había llegado el fin de esa urbe (Dolan, 2001). Como sea, sobre el modo de acabar con el fuego, lo que se sabe es que solo se logró gracias a la creación de cortafuegos ejecutados con el derribamiento de algunas edificaciones que estaban en el camino del fuego. Un alto funcionario, Samuel Pepys, había propuesto esa idea (Thrower, 2003), pero dado que implicaba demoler propiedad privada, Thomas Bloodworth (alcalde de Londres en ese momento) se entregó al beneficio de la duda hasta que el rey Carlos II señaló que era un paso necesario (Tinniswood, 2004: 51-52).

Las pérdidas materiales fueron descomunales; el gran fuego dio lugar a un fuerte endeudamiento, lo cual exigió una importante reacuñación del total de la moneda en 1669. Pero al mismo tiempo, de las cenizas surgieron nuevas posibilidades para la ciudad y la nación. Las ruinas de Londres fueron reemplazadas por un proceso de renovación que trajo una planificación moderna e inédita. Alrededor de una de cada tres edificaciones que había sido tocada o afectada por el fuego fue eliminada definitivamente del nuevo trazado urbano. Gracias a la aparición de más espacio disponible, se crearon zonas funcionales (con mercados distribuidos en varios puntos, pero creando también una gran zona comercial en toda el área del centro) y se optó por construir vías más amplias y utilizar materiales menos propensos a ser dañados, lo cual redundó en la (re)configuración de una metrópolis más organizada, que también implicó una primitiva forma de gentrificación, ya que la flamante disposición espacial obligó a las masas a moverse a los márgenes, mientras los sectores más ricos fueron eligiendo retirarse del centro a espacios menos transitados (Spate, 1936).

Como se observa, en definitiva, el incendio modificó radicalmente la vida y las ideas acerca de la convivencia entre sociedad y naturaleza en el contexto británico. Podría incluso afirmarse que fue uno de los primeros impulsos hacia el imperialismo inglés que se expresaría de manera más acabada en el siglo XIX (Spate, 1936). Pero ese no fue el único efecto de las llamas... 


\section{IV. ¿Cortafuegos o bomberos?}

Las resistencias al uso de cortafuegos riñen en algún sentido con un postulado de John Locke, un pensador con claras influencias en la obra de Smith y en la historia del liberalismo, que fue contemporáneo del gran incendio y aparentemente alcanzó a ver la humareda desde Oxford. En su segunda formulación acerca de la ley natural, Locke sostiene que, si bien la naturaleza se encontraba al servicio de la humanidad para ser apropiada y aprovechada en pos de un desarrollo creciente de los hombres trabajadores, también es deber de cada individuo preservar al resto de sus congéneres. Su lectura de la naturaleza no solo se opone a la competencia destructiva, sino que también insta a hacer un aporte a la mutua protección:

Aunque la tierra y todas las criaturas inferiores pertenecen en común a todos los hombres, cada hombre tiene, sin embargo, una propiedad que pertenece a su propia persona; y a esa propiedad nadie tiene derecho, excepto él mismo. El trabajo de su cuerpo y la labor producida por sus manos podemos decir que son suyos. Cualquier cosa que él saca del estado en que la naturaleza la produjo y la dejó, y la modifica con su labor y añade a ella algo que es de sí mismo, es, por consiguiente, propiedad suya. Pues al sacarla del estado común en el que la naturaleza la había puesto, agrega a ella algo con su trabajo [...] [y] da como resultado el que ningún hombre, excepto él, tenga derecho a lo que ha sido añadido a la cosa en cuestión, al menos cuando queden todavía suficientes bienes comunes para los demás (Locke, 2006: 34).

Para Locke, la tendencia a la apropiación y usufructo privados de la propiedad son cruciales para la decisión colectiva de establecer un sistema de gobierno y salir del estado natural. El papel principal del gobierno es el de asegurar al individuo y a la especie su derecho natural a la autoconservación y al crecimiento. El Estado no inventa la propiedad privada ni permite su existencia, sino que la defiende, por ser un derecho natural no consensual de los individuos. De hecho, los Estados, para Locke, funcionan si logran regular la propiedad privada y garantizar cierta justicia frente a los abusos. Pero de ningún modo concibe a la propiedad como una noción legal, lo cual justificaría la modificación colectiva de sus reglas, sino como un derecho (e incluso como una obligación) natural que las instituciones deben facilitar y conservar.

Al mismo tiempo, existe en este autor una estructura que limita la posibilidad de acumular propiedad indefinidamente. En el estado de 
abundancia natural, cada cual tiene derecho de adquirir tanto como pueda trabajar y usar, siempre y cuando esto garantice que haya disponibilidad (en cantidad y calidad) de tierras y bienes para el resto (Locke, 2006: 34). Y en la era de la escasez de tierras (dentro de la sociedad política establecida, después de la introducción del dinero y la apropiación de todo el terreno disponible), los propietarios están obligados a emplear a los sin tierra, para que estos últimos puedan vivir de su trabajo (Locke, 2006: 48). Del mismo modo, Locke sostiene que en una situación de guerra o ante la obligación de resarcir justamente a alguien, es central garantizar la subsistencia del resto.

\begin{abstract}
Como la ley fundamental de naturaleza dice que ha de procurarse la conservación de todos hasta donde sea posible, a ello se sigue que si no hay bienes suficientes para satisfacer a la vez los derechos del vencedor y los de los hijos, quien tenga ya bienes de sobra para mantenerse habrá de ceder algo de su completa indemnización, y dárselo a quienes tienen mayor y más urgente derecho, debido a que estarían en peligro de perecer si careciesen de esos bienes (Locke, 2006: 181).
\end{abstract}

Con eso en mente, y con la salvedad de que los cataclismos no entraron realmente al discurso filosófico moderno por lo menos hasta la última parte del siglo XVIII, se pueden tomar en consideración algunas palabras de Robert Nozick, quien halló en Locke una fuente para sus propios razonamientos. Nozick enunció el problema que una catástrofe natural plantea frente a la propiedad privada, ya que la sociedad queda en una situación en la cual resulta necesario reorganizar la propiedad de modo que haya suficiente para todos (Nozick, 1974: 180).

Según este autor, en Locke hay dos condiciones para la propiedad privada, una más fuerte (alguien puede apropiarse de algo solo si hay suficiente para que otros hagan lo mismo) y una más débil (alguien puede poseer algo si eso hace que todos los que participan del sistema estén en mejores condiciones de lo que estarían si no existiera tal sistema). Nozick analiza casos de desastres naturales y sugiere que una catástrofe "pone en funcionamiento la salvedad [débil] de Locke y limita los derechos de propiedad" (Nozick, 1974: 179). Dicho en términos simples, se puede hallar en Locke un espacio para la redistribución de bienes por fuera de las reglas "normales" de los derechos naturales. A partir de eso, es dable pensar que, en la doctrina moderna proto-liberal, si bien está centrada en la idea de individuos con derechos, existe una concepción de la sociedad (o incluso la especie humana) por la que es posible, en algunos casos, limitar la 
propiedad privada en pos de un bien mayor. Sin embargo, esta idea fue, en los hechos, opacada por acciones que consiguieron sortear ese ideal.

En vistas de lo anterior, un ejemplo por demás sugerente tiene que ver con el arribo de brigadas de bomberos de la ciudad de Londres. Analizarlo puede servir para recordar que existió una respuesta derivada de la catástrofe ígnea de 1666, a la que tal vez se le ha dado menor envergadura de la que se merece. Las cuadrillas no aparecieron por iniciativa de las autoridades municipales o nacionales, sino que fueron iniciativas privadas con fines de lucro. Su génesis estuvo vinculada con una serie de omisiones y dichos del rey Carlos II, que revelaban que no sería capaz de proveer a la capital británica los bienes y servicios necesarios para poder evitar o contrarrestar incendios como el que había ocurrido ${ }^{1}$.

La evolución de la lucha contra las llamas de la Londres moderna estuvo vinculada con la expansión de una creciente actividad (que, de hecho, acompañó de cerca todo el proceso modernizador en Europa): los seguros. La forma que tomaron estas empresas era similar a la de las aventuras comerciales marítimas (con los consecuentes seguros para el transporte) que habían crecido desde el siglo XIII y que hallaron un desarrollo exponencial con la explotación del continente americano. Las compañías aseguradoras ocuparon un lugar vacante y necesario y utilizaron, además, métodos que no pondrían en riesgo la propiedad privada.

La aparición de las brigadas semipúblicas tuvo importantes efectos sobre la sociedad toda. A partir de una serie de cálculos, las empresas comprendieron que crear un cuerpo de bomberos bien entrenados era muy conveniente para ahorrar a la hora de tener que reconstruir las viviendas de sus clientes. Pero además, esto trajo aparejado el triunfo de una apelación a la conciencia individual y no a la idea de bien común, por lo que no contratar seguros podía ser interpretado como falta de cuidado o desdén y, por lo tanto, culpabilizado (Ewald, 1991).

De igual forma, existió un período (que podría llamarse "publicitario") en el que las brigadas ayudaron a apagar fuegos en sitios públicos o no asegurados. Pero al tiempo fueron colocando un símbolo (un sol) en las puertas de quienes poseían pólizas, para que las guardillas priorizaran esas construcciones sobre las otras, o, directamente, para que solo se dedicaran a ellas. Evidentemente, eso movilizó a la opinión pública, ya que, poco tiempo después, una de cada tres viviendas había adquirido algún seguro contra las llamas. Se ve así que el trauma por el fuerte impacto 
material y simbólico al que habían quedado expuestos los sobrevivientes del incendio fue utilizado a favor de una nueva organización urbana y una privatización de la ayuda contra el fuego y sus efectos.

\section{Smith y el Estado frente a la catástrofe}

En las páginas anteriores se ha delineado un derrotero establecido con el fin de encuadrar ciertos cruces entre ley natural y ley civil en el pensamiento de Smith, especialmente en la instancia límite de una catástrofe que exige forzar una toma de partido para arribar a una solución.

La cita más señalada cuando se comenta esta cuestión es la referencia a un supuesto terremoto en China. Tal vez inspirado por el ya mencionado temblor de Lisboa de 1755 (la Teoría de los sentimientos morales fue escrita en los años exactamente posteriores a ese evento), Smith pensó en China por ser un lugar casi inimaginable de visitar para un británico medio del siglo XVIII (el viaje, en barco, duraba alrededor de un año). En ese célebre ejercicio de imaginación, Smith se pregunta cómo reaccionaría un europeo a la potencial muerte de millones de personas que no conoce:

Supongamos que el enorme imperio de la China, con sus miríadas de habitantes, súbitamente es devorado por un terremoto, y analicemos cómo sería afectado por la noticia de esta terrible catástrofe un hombre humanitario de Europa, sin vínculo alguno con esa parte del mundo. Creo que ante todo expresaría una honda pena por la tragedia de ese pueblo infeliz, haría numerosas reflexiones melancólicas sobre la precariedad de la vida humana y la vanidad de todas las labores del hombre, cuando puede ser así aniquilado en un instante. Si fuera una persona analítica, quizá también entraría en muchas disquisiciones acerca de los efectos que el desastre podría provocar en el comercio europeo y en la actividad económica del mundo en general. Una vez concluida esta hermosa filosofía, una vez manifestados honestamente esos filantrópicos sentimientos, continuaría con su trabajo o su recreo, su reposo o su diversión, con el mismo sosiego y tranquilidad como si ningún accidente hubiese ocurrido. El contratiempo más frívolo que pudiese sobrevenirle daría lugar a una perturbación mucho más auténtica. Si fuese a perder su dedo meñique mañana, no podría dormir esta noche (Smith, 1997: 259-260).

Smith afirma que las catástrofes solo son percibidas en toda su magnitud por quienes son directamente afectados por ellas. Sin embargo (o, por eso mismo) comprende que esta dimensión subjetiva y pasional debe ser 
superada racionalmente para lograr mantener viva a la sociedad y a sus miembros:

No es el apagado poder del humanitarismo, no es el tenue destello de la benevolencia que la naturaleza ha encendido en el corazón humano lo que es así capaz de contrarrestar los impulsos más poderosos del amor propio. Lo que se ejercita en tales ocasiones es un poder más fuerte, una motivación más enérgica. Es la razón, el principio, la conciencia, el habitante del pecho, el hombre interior, el ilustre juez y árbitro de nuestra conducta. Él es quien, cuando estamos a punto de obrar de tal modo que afecte la felicidad de otros, nos advierte con una voz capaz de helar la más presuntuosa de nuestras pasiones que no somos más que uno en la muchedumbre y en nada mejor que ningún otro de sus integrantes, y que cuando nos preferimos a nosotros mismos antes que a otros, tan vergonzosa y ciegamente, nos transformamos en objetivos adecuados del resentimiento, el aborrecimiento y la execración (Smith, 1997: 260).

Como se mencionaba antes, el espectador imparcial (cima de la simpatía y la racionalidad) es una instancia que opera hacia el bien común, incluso si eso afecta su legítima búsqueda de bienestar personal. Es el espejo moral al que todos deberían, según Smith, apuntar. Es importante tener esto en cuenta al leer su referencia al fuego:

Acaso habrá quien sostenga que impedir que un particular reciba en pago los billetes de un Banco, por una suma grande o pequeña, cuando no tiene inconveniente en aceptarlos, o prohibir a un banquero que los emita cuando los demás no tienen inconveniente en recibirlos, es un atentado contra la libertad natural, que la ley viene obligada a proteger y no a violar. Estas reglamentaciones pueden considerarse indiscutiblemente como contrarias a la libertad natural. Pero el ejercicio de esta libertad por un contado número de personas, que puede amenazar la seguridad de la sociedad entera, puede y debe restringirse por la ley de cualquier Gobierno, desde el más libre hasta el más despótico. La obligación de construir muros para impedir la propagación de los incendios es una violación de la libertad natural, exactamente de la misma naturaleza que las regulaciones en el comercio bancario de que acabamos de hacer mención (Smith, 1997: 293)².

Smith expresa claramente que la concentración de libertad (incluso de "libertad natural") en manos de unos pocos -normalmente en su obra, los más ricos- amenaza a la sociedad en su conjunto. Por lo tanto, es 
obligación de los Estados limitarla, incluso con medidas "antinaturales" y anteponer la búsqueda de la riqueza nacional a la particular. Con esto, se puede percibir que para Smith no existe una economía "pura" (en contraposición a una economía política), sino un entramado entre naturaleza y su regulación para provecho de las naciones.

De hecho, constan pasajes de La riqueza de las naciones en los que Smith opta por la regulación del comercio exterior (Smith, 1996: 256)3, libro en el que tampoco se descarta la posibilidad de que puedan existir administradores honestos de lo público. Y sin embargo, nuevamente, la naturaleza presenta para Smith también aspectos negativos. Incluso los malos gobiernos parecerían pertenecer a ella: "la violencia e injusticia de los gobernantes de la humanidad es un mal muy antiguo, y mucho me temo que apenas tenga remedio en la naturaleza de los asuntos humanos" (Smith, 1996: 564)4.

Desde la perspectiva de Smith, la sociedad está compuesta por actores concretos, determinados, con diferentes posibilidades, deseos y necesidades. Por eso, en su obra convive la idea de que ninguna ley civil puede modificar demasiado la tasa de interés que conforma el mercado (Smith, 1996: 140149), con una crítica a los abusos de poder económico que insta a balancearlos cuando llegan a poner en peligro la vida en común. Hay que tener presente que las interferencias de todo tipo en la competencia, así como las alianzas entre las autoridades políticas y el poder económico en la época de Smith estaban a la orden del día (Viner, 2012). De modo que sus críticas parecen posarse sobre cualquier concentración excesiva (así sea de libertad).

Un elemento que puede aportar a este argumento es la admiración expresada por Smith a Rousseau, de quien fue contemporáneo, en The Edinburgh Review de 1756 (Lomonaco, 2002: 659). Allí, en una carta de lector, el británico recomienda la lectura del ginebrino y ensalza su figura ${ }^{5}$. Un año antes, Rousseau había escrito frases como estas:

Siempre existirá una diferencia extrema entre el gobierno doméstico, en el cual el padre puede verlo todo por sí mismo, y el gobierno civil, en el cual el jefe lo ve casi todo mediante ojos ajenos. [...] Los deberes del padre le son dictados por sentimientos naturales y de forma tal que raramente le es permitido desobedecer. [...] Nada de todo lo anterior existe en la sociedad política, la cual, lejos de tener un interés natural en la felicidad de 
los particulares, busca con frecuencia el suyo propio en la miseria de estos (Rousseau, 2001: 4-6).

Algunos años más tarde, en su Contrato social, Rousseau desarrollaría ideas ya presentes en sus reflexiones sobre economía política y postularía que el ingreso a la vida civil, nacional y estatal estaba íntimamente vinculado con las posibilidades de lidiar con la naturaleza:

\begin{abstract}
Supongo a los hombres llegados al punto en que los obstáculos que impiden su conservación en el estado natural superan las fuerzas que cada individuo puede emplear para mantenerse en él. Entonces este estado primitivo no puede subsistir, y el género humano perecería si no cambiara su manera de ser. Ahora bien, como los hombres no pueden engendrar fuerzas nuevas, sino solamente unir y dirigir las que existen, no han tenido para conservarse otro medio que formar por agregación una suma de fuerzas que pueda superar la resistencia, ponerlas en juego mediante un solo móvil y hacerlas obrar a coro (Rousseau, 1996: 21-22).
\end{abstract}

En esas palabras existen coincidencias con Smith, en tanto que se apela a un esfuerzo común como medio de preservar la vida de cada individuo.

\title{
VI. Nota final
}

Adam Smith es un eslabón fundamental del liberalismo e incluso hay quienes lo colocan entre los agentes necesarios del capitalismo. Una asunción de tal naturaleza solo es posible bajo dos condiciones: en primer lugar, matizando las "responsabilidades", atendiendo a su mirada general y a sus opiniones acerca de los vínculos entre Estado y mercado. Y en segundo lugar, contemplando de cerca el derrotero interpretativo que siguieron sus obras.

En los escritos de Smith no es posible hallar un propósito sintético (aunque sí sistemático), ni la intención de describir una realidad abstracta y permanente. Opuestamente, el estilo de sus análisis responde a un examen de la realidad factual, cuyas regularidades (relativas en el tiempo y el espacio) no son necesariamente leyes invariables. Por eso, su mirada acerca del aspecto monetario (sobre el que se ocupa bastante), que muestra que es malo para la sociedad (en términos de producción, competencia, etcétera) que se desregule totalmente la emisión privada, se complementa con una 
reflexión menos técnica y más moral, con las mismas conclusiones. La naturaleza autorreguladora del mercado ocupa un gran lugar en el pensamiento de Smith, pero no hay que descuidar los límites que él mismo supuso necesario imponer a esa naturaleza. No debemos olvidar que, como se ha visto, "lo natural" en Smith es un concepto polimorfo.

Finalmente, en un mundo, como el actual, en el que la concentración económica, la inequidad y los abusos de poder se encuentran en niveles realmente preocupantes, volver sobre los textos de Smith puede ayudarnos a profundizar la reflexión y las posibles vías de acción para defender a las sociedades por encima de los intereses particulares.

\section{Referencias Bibliográficas}

Anderson, G. M., Shughart, W. F. \& Tollison, R. D. (1985). "Adam Smith in the Customhouse”. Journal of Political Economy, 93(4), 740-759.

Clout, H. (2000). The Times History of London. Ammanford: Ted Smart.

Cockerell, H. A. L. \& Green, E. (1994). The British Insurance Business, 15471970: An Introduction and Guide to its History and Records in the United Kingdom. Sheffield: Sheffield Academic Press.

Committee to Enquire into the Burning of London, House of Commons. Parliament of England and Wales (1667). A True and Faithful Account of the Several Informations exhibited to the Honourable Committee appointed by the Parliament to Inquire into the Late Dreadful Burning of the City of London. Together with other Informations touching the Insolency of Popish Priests and Jesuites; and the Increase of Popery, brought to the Honourable Committee appointed by the Parliament for that purpose. Recuperado de: http://name.umdl.umich.edu/A63385.0001.001. Último acceso: marzo 2021.

Cremaschi, S. (1989). "Adam Smith: Skeptical Newtonianism, Disenchanted Republicanism, and the Birth of Social Science". En Dascal, M. \& Gruengard, O. (Eds.). Knowledge and Politics: Case Studies in the Relationship Between Epistemologv and Political Philosophy. Boulder: Westview Press.

Davis, E. J. (1923). “The Great Fire of London”. History, 8(29), 40-44.

Dolan, F. E. (2001). "Ashes and 'the Archive': The London Fire of 1666, Partisanship and Proof". Journal of Medieval and Early Modern Studies, 31(2), 379-408.

Ewald, F. (1991). "Insurance and Risks". En Burchell, C., Gordon, C. \& Miller, P. (Eds.). The Foucault Effect; Studies in Governmentality (pp. 197-210). Londres: Harvester.

Gilpin, J. (2013). "God's Terrible Voice: Liturgical Response to the Great Fire of London”. Anglican and Episcopal History, 82(3), 318-334. 
Hobbes, T. (1987) [1650]. "La naturaleza humana o los elementos fundamentales de la política”. En Lynch, E. (Ed.). Antología Hobbes (pp. 127-178). Barcelona: Península.

Hobbes, T. (1996) [1651]. Leviatán. O la materia, forma y poder de un Estado eclesiástico y civil. Madrid: Alianza.

Hume, D. (1983). The History of England from the Invasion of Julius Caesar to the Revolution in 1688 (vol. 6). Indianapolis: Liberty Fund. Recuperado de: http://oll.libertyfund.org/titles/793\#Hume_oo11-06_725. Último acceso: marzo 2021.

Jonsson, F. A. (2010). "Rival Ecologies of Global Commerce: Adam Smith and the Natural Historians". The American Historical Review, 115(5), 1342-1363.

Locke, J. (2006). Segundo Tratado sobre el Gobierno Civil Un ensayo acerca del verdadero origen, alcance y fin del Gobierno Civil. Madrid: Tecnos.

Lomonaco, J. (2002). "Adam Smith's 'Letter to the Authors of the Edinburgh Review". Journal of the History of Ideas, 63(4), 659676.

Maitland, W. (2010). The history and survey of London from its foundation to the present time (vol. I). Londres: Gale ECCO.

Malthus, T. R. (1798). An essay on the principle of population. Recuperado de:

https://archive.org/details/essayonprinciploomalt/page/n7/mode/ 2up. Último acceso: marzo 2021.

Maquiavelo, N. (1984). El príncipe. Madrid: Alianza.

Nolan, P. (2003). "Adam Smith and the Contradictions of the Free Market". Challenge, 46(3), 112-123.

Nozick, R. (1974). Anarchy, State, and Utopia. Nueva York: Basic Books.

Ottonello, R. (2019). "Los insensibles y lo Invisible en La riqueza de las naciones”. En Borisonik, H. et al. Detrás del espectador imparcial: ensayos en torno de Adam Smith (pp. 21-36). Buenos Aires: CLACSO-IIGG.

Pack, S. (1995). “Adam Smith's Unnaturally Natural (nonetheless Naturally Unnatural) use of the Word Natural". The Classical Tradition in Economic Thought: Perspectives on the History of Economic Thought (vol. XI), 31-42.

Paszkowski, W. (1890). Adam smith als moralphilosoph. Recuperado de https://archive.org/details/adamsmithalsmoraoopaszuoft/mode/2 up. Último acceso: marzo 2021.

Piqué, P. (2019). "El legado teórico de Adam Smith en los manuales universitarios de historia del pensamiento económico". En Borisonik, H. et al. Detrás del espectador imparcial: ensayos en torno de Adam Smith (pp. 193-214). Buenos Aires: CLACSO-IIGG.

Ricardo, D. (1817). On the Principles of Political Economy and Taxation. Londres: John Murray. Recuperado de: 
https://www.econlib.org/library/Ricardo/ricP.html. Último acceso: marzo 2021.

Rousseau, J-J. (1996). Del contrato social. Madrid: Alianza Editorial.

Rousseau, J-J. (2001). Discurso sobre economía política. Madrid: Tecnos. Say, J-B. (2011) [1803]. Traité d'Économie Politique. París: Institut Coppet. Small, A. W. (1907). Adam Smith and Modern Sociology: A Study in the Methodology of the Social Sciences. Chicago: The University of Chicago Press. Recuperado de: https://archive.org/details/adamsmithandmodoosmalgoog/page/n 8/mode/2up. Último acceso: marzo 2021.

Smith, A. (1996). La riqueza de las naciones. Madrid: Alianza.

Smith, A. (1997). La teoría de los sentimientos morales. Madrid: Alianza Editorial.

Smith, A. (1982a). The Theory of Moral Sentiments. Liberty Fund. Recuperado de: https://oll.libertyfund.org/title/smith-the-theoryof-moral-sentiments-and-on-the-origins-of-languages-stewart-ed. Último acceso: marzo 2021.

Smith, A. (1982b). Lectures On Jurisprudence. Indianapolis: Liberty Fund.

Smith, A. (1982c). "Letter to the Edinburgh Review". Recuperado de: http://ml.ci.uc.pt/mhonarchive/histport/pdfEDITv6oEvu.pdf. Último acceso: abril 2021.

Spate, O. H. K. (1936). "The growth of London, 1660-180o". En Darby, H. C. (Ed.). An historical geography of England before 1800 (pp. 529548). Cambridge: Cambridge University Press.

Stillingfleet, E. (1666). A sermon preached before the honourable House of Commons at St. Margarets Westminster, Octob. 10, 1666 being the fast-day appointed for the late dreadfull fire in the city of London. Recuperado

http://quod.lib.umich.edu/e/eebo/A61600.0001.oo1. de acceso: marzo 2021.

Steuart, J. (1767). An Inquiry into the Principles of Political Economy. Recuperado de: https://www.marxists.org/reference/subject/economics/steuart/in dex.htm. Último acceso: marzo 2021.

Thrower N. J. W. (2003). "Samuel Pepys F.R.S. (1633-1703) and the Royal Society". Notes and Records of the Royal Society of London, 57(1), 3-13.

Tinniswood, A. (2004). By Permission of Heaven: The Story of the Great Fire of London. Londres: Random House.

Viner, J. (2012). "Adam Smith and Laissez Faire". En Clark, J. M. \& Douglas, P. H. Adam Smith, 1776-1926: Lectures to commemorate the sesquicentennial of the publication of The Wealth of Nations. Whitefish: LLC.

Walker, M. F. (2011). "The Limits of Collaboration: Robert Hooke, Christopher Wren and the Designing of the Monument to the Great 
Fire of London". Notes and Records of the Royal Society of London, 65(2), 121-143.

\begin{abstract}
${ }^{1}$ Estos y, en general, todos los datos históricos utilizados para este apartado (excepto cuando se aclare otra fuente) surgen de Cockerell y Green (1994).

2 "Restrain private people, it may be said, from receiving in payment the promissory notes of a banker, for any sum whether great or small, when they themselves are willing to receive them; or, to restrain a banker from issuing such notes, when all his neighbours are willing to accept of them, is a manifest violation of that natural liberty which it is the proper business of law, not to infringe, but to support. Such regulations may, no doubt, be considered as in some respect a violation of natural liberty. But those exertions of the natural liberty of a few individuals, which might endanger the security of the whole society, are, and ought to be, restrained by the laws of all governments; of the most free, as well as of the most despotical. The obligation of building party walls, in order to prevent the communication of fire, is a violation of natural liberty, exactly of the same kind with the regulations of the banking trade which are here proposed" (Smith, 1982a: 324).

3 Para profundizar sobre esta cuestión, ver el artículo de Anderson, Shughart y Tollison (1985: 754-756).

4 Acerca de la simplificación de la naturaleza realizada por Smith (incluso a sabiendas de sus aristas más complejas, dinámicas y contradictorias), ver Jonsson (2010).

5 "Los ingleses de la época actual, desesperados quizás por superar los inventos o igualar el renombre de sus antepasados, han desdeñado ocupar el segundo lugar en una ciencia en la que no pudieron llegar al primero, y parecen haber abandonado el estudio de ella por completo. [...] El Sr. Hobbes, el Sr. Locke y el Dr. Mandeville, Lord Shaftesbury, el Dr. Butler, el Dr. Clarke y el Sr. Hutcheson, todos ellos, de acuerdo con sus diferentes e inconsistentes sistemas, se han esforzado al menos por ser, en alguna medida, originales y añadir algo a ese acervo de observaciones que el mundo había recibido antes que ellos. Esta rama de la filosofía inglesa, que ahora parece estar completamente descuidada por los propios ingleses, ha sido últimamente transportada a Francia. Observo algunos rastros de ella, no solo en la Enciclopedia, sino en la Teoría de los sentimientos agradables del Sr. De Pouilly, una obra que en muchos aspectos es original; y, sobre todo, en el reciente Discurso sobre el origen y los fundamentos de la desigualdad entre los hombres del Sr. Rousseau de Ginebra” (Smith, 1982c: $246 ; 250)$.
\end{abstract}

